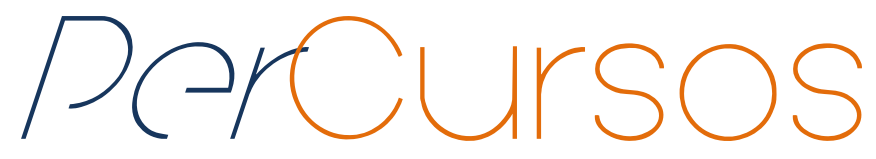

\title{
CONFINTEA VI e as políticas de educação para jovens e adultos em Santa Catarina ${ }^{1}$
}

\section{Resumo}

O artigo reúne conclusões de dois projetos de pesquisa desenvolvidos sequencialmente. O primeiro tratou do paradigma de educação ao longo da vida nas políticas educacionais para Jovens e Adultos no Brasil na primeira década do século XXI, visando perceber as suas diferentes abordagens, influências e alcances. O segundo tratou das repercussões e influências da CONFINTEA VI nas Políticas de Educação para Jovens e Adultos em Santa Catarina. Para isso, utilizou-se a metodologia de análise documental e referenciais de análise das políticas educacionais que permitissem investigar os processos de difusão, assimilação e incorporação de determinados conceitos no bojo das reformas educacionais. Das análises, destacam-se o reconhecimento de que a VI CONFINTEA é considerada nos planos nacional e internacional o principal agente de indução das políticas para a EJA, colocando-se como um arauto para a concretização da educação e aprendizagem ao longo da vida. Todavia, tais processos de disseminação dependem fundamentalmente dos contextos locais, resultando num complexo processo entre os agentes nacionais e internacionais, nomeadamente entre a UNESCO, o Ministério da Educação (MEC) e a Secretaria de Educação Continuada, Alfabetização, Diversidade e Inclusão (SECADI), Secretarias Estaduais e Municipais de Educação e Fóruns de EJA do Brasil. Na busca de aprofundamento sobre esse processo de formulação e disseminação da política, analisou-se as linhas de continuidades, divergências e rupturas no que concerne às diretrizes da CONFINTEA VI, bem como, os processos de convergências e disputas em torno da concepção de educação e aprendizagem ao longo da vida.

Palavras-chave: Educação de jovens e adultos - Santa Catarina; Conferência internacional de educação de adultos; Educação e aprendizagem ao longo da vida.

\author{
Marilda Merência Rodrigues \\ Doutora em Educação pela \\ Universidade Federal de Santa \\ Catarina - UFSC. \\ Professora da \\ Universidade Federal da \\ Fronteira Sul- UFFS/SC. \\ Brasil \\ marilda@uffs.edu.br
}

Jéssica Vanessa Cavalheiro
Graduada em Pedagogia
pela Universidade Federal da
Fronteira Sul - UFFS/SC.
Brasil
jessy.v.c@hotmail.com

\footnotetext{
1 Este trabalho sistematiza conclusões oriundas de dois projetos de pesquisa desenvolvidos sequencialmente. O primeiro, com apoio do Programa de Iniciação Científica - PIBIC/UFFS, investigou o paradigma de educação ao longo da vida nas políticas educacionais para Jovens e Adultos no Brasil na primeira década do século XXI, visando perceber as suas diferentes abordagens, influências e alcances. $O$ segundo com apoio do Programa Institucional de Iniciação Científica - PIICT/UFFS, tratou das repercussões e influências da CONFINTEA VI nas Políticas de Educação para Jovens e Adultos em Santa Catarina. Uma versão desse trabalho foi apresentada na XI Jornada do HISTEDBR - A Pedagogia Histórico-crítica, a Educação Brasileira e os desafios da sua institucionalização (2013).
} 


\title{
CONFINTEA VI and education policies for youth and adults in Santa Catarina
}

\begin{abstract}
The paper presents findings of two research projects developed sequentially. The first dealt with the education paradigm lifelong educational policies for Youth and Adults in Brazil in the first decade of this century, seeking to understand their different approaches, influences and scope. The second dealt with the effects and influences of CONFINTEA VI in Education Policies for Youth and Adults in Santa Catarina. For this, we used the documentary analysis methodology and educational policy analysis frameworks that enable investigate diffusion processes, assimilation and incorporation of certain concepts at the core of the educational reforms. The analysis, it highlights the recognition that CONFINTEA $\mathrm{VI}$ is considered the national and international levels the main policies induction agent for EJA, posing as a herald for the implementation of education and learning throughout life. However, such dissemination processes depend mainly of local contexts, resulting in a complex process between national and international actors, notably between UNESCO, the Ministry of Education (MEC) and the Department of Continuing Education, Literacy, Diversity and Inclusion (SECADI), State Departments and Municipal Education and Forums EJA Brazil. In seeking to deepen on this formulation and dissemination of policy, it analyzed the lines of continuities, ruptures and divergences with regard to the directives of CONFINTEA $\mathrm{VI}$ and the convergence process and disputes over education design and lifelong learning.
\end{abstract}

Keywords: Youth and adult education - Santa Catarina; International conference on adult education; Education and learning throughout life.

\section{Para citar este artigo:}

RODRIGUES, Marilda Merência; CAVALHEIRO, Jéssica Vanessa. CONFINTEA VI e as políticas de educação para jovens e adultos em Santa Catarina. Revista PerCursos. Florianópolis, v. 16, n.31, p. 137 - 158, maio/ago. 2015.

\section{DOI: $10.5965 / 1984724616312015137$}

http://dx.doi.org/10.5965/1984724616312015137 


\section{Introdução}

Estudar o conteúdo das reformas educacionais e os seus mecanismos de difusão tem sido uma tarefa enfrentada por alguns pesquisadores brasileiros, a exemplo de Shiroma, Moraes e Evangelista (2002), Shiroma, Campos e Garcia (2005) e Neves (2005), dentre outros, cujas preocupações resultam de uma percepção da política educacional tomada não apenas na sua imediaticidade, traduzida na legislação ou nas relações cotidianas institucionalizadas. Mas, sobretudo, da sua compreensão no processo histórico da educação brasileira marcado por disputas, tão bem demonstradas por Cury (2005), em cuja contenda destacam-se "quatro senhores educacionais", a Iniciativa Privada, o Estado, a Família e a Igreja. Essa disputa parece ter, de fato, tomado outras feições na contemporaneidade ou se complexificado sobremaneira, como pensa Melo (2005) ao evidenciar os organismos internacionais no processo de condução de um novo bloco histórico, expondo que "as diferenças entre público e privado, entre indivíduo e coletividade [...] confundem-se nesse projeto capitalista de sociabilidade" (MELO, 2005, p. 69), e que, para a manutenção de uma hegemonia ativa, "de direção e dominação indissociadas, exige uma complexa disciplina de planejamento e formação de consenso" (MELO, 2005, p. 69).

Esse processo ativo de formação de consensos tem nos preocupado, em especial, a assimilação e incorporação de determinados conceitos no bojo das reformas educacionais, como ocorre com o conceito de educação e aprendizagem ao longo da vida, que vem alcançando um grau de circulação e assimilação ancorado em três eixos principais de argumentação: como mecanismo de promoção do respeito às necessidades e diferenças individuais; instrumento de democratização da educação e chave de acesso ao século XXI, capaz de promover a participação do sujeito na modernidade global.

No âmbito da educação de jovens e adultos, esse conceito foi transformado em paradigma educacional a ser perseguido, tendo como porta principal de entrada a VI Conferência Internacional de Educação de Adultos (CONFINTEA), realizada no Brasil em 2009. Note-se, porém, que em abril de 2008, no âmbito da Conferência Nacional da Educação Básica (CONEB), realizada em Brasília, esse tema já havia aparecido, embora 
ainda tímido, no primeiro eixo temático da Conferência, Construção do Sistema Nacional Articulado de Educação, como orientação para reconfiguração dos sistemas educacionais no Brasil.

Mais diretamente voltado às políticas de educação de jovens e adultos, tal conceito vinculava-se à ideia de consolidação dessa modalidade, "concretizada na garantia de formação integral, da alfabetização e das demais etapas de escolarização, ao longo da vida, inclusive àqueles em situação de privação de liberdade" (CONFERÊNCIA, 2008b, p. 19). Nessa perspectiva de consolidação, apontava-se no referido documento, dentre outros aspectos, a isonomia financeira da EJA em relação às demais modalidades da educação básica e uma política de formação permanente para o professor atuante na modalidade (CONFERÊNCIA, 2008b), aspectos estes reiterados nos documentos de referência para debate (CONFERÊNCIA, 2008a), bem como, no relatório final (CONFERÊNCIA, 2008c), no quais a referida concepção de educação é associada à ideia de ampliação e diversificação de espaços e tempos pedagógicos.

Em que pese a relevância dessas orientações, emanadas inclusive dos Fóruns estaduais de EJA, não parece haver uma compreensão uniforme ou razoavelmente satisfatória sobre os sentidos da consolidação da EJA no Brasil tomando como referência a perspectiva de uma educação e aprendizagem ao longo da vida, expressões por vezes mencionadas como referindo-se ao mesmo processo ${ }^{2}$.

Há que se considerar, entretanto, que a imprecisão em torno desses conceitos consubstanciados em slogans educacionais e como base de sustentação de um novo paradigma de política educacional não é privilégio nacional. Tal perspectiva educacional tem sido disseminada amplamente pelos canais de difusão da UNESCO como mecanismo para consecução da política de Educação para Todos, abarcando desde aspectos subjetivos, como fator responsável pela cultura da paz, por exemplo, ou à constituição de um sujeito com espírito empresarial capaz de resolver os perigos potenciais do

\footnotetext{
${ }^{2}$ Para um aprofundamento dessas expressões consubstanciadas em slogans educacionais sugere-se a leitura de RODRIGUES, M. M. Matrizes e repercussões da Educação ao Longo da vida como política educacional. In: EVANGELISTA, Olinda (Org.). O que revelam os slogans na política educacional. SP: Junqueira \& Marin, 2014, p. 203-243.
} 
desemprego. De outro lado, mas não exatamente em oposição, a aprendizagem ao longo da vida tem sido associada, no âmbito da Comissão das Comunidades Europeias, à possibilidade de desenvolvimento de um espírito empreendedor, capaz de assegurar o posicionamento do bloco na chamada "sociedade do conhecimento".

Se estendermos esse debate em torno da imprecisão desse conceito consubstanciado em orientação para políticas educacionais, chegamos propriamente ao eixo central de nossas preocupações, quais sejam, as repercussões e influências da CONFINTEA VI nas políticas de educação para Jovens e Adultos em Santa Catarina. Para isso, faremos uma breve incursão sobre a história das Conferências Internacionais de Adultos, remetendo-nos em especial, a VI CONFINTEA, realizada no Brasil em 2009, explorando um conjunto de documentos emanados desse evento, bem como, das etapas preparatórias resultantes do trabalho no Fórum Regional de EJA em Santa Catarina.

\section{Um breve histórico das CONFINTEAs}

Para uma melhor compreensão do tema aqui exposto é conveniente trazer uma breve contextualização das Conferências Internacionais de Educação de Adultos realizadas até o ano de 2009. Já que estas, como conferências orientadas pela UNESCO, têm sido a principal via disseminadora de diretrizes para as políticas voltadas à Educação de Jovens e Adultos.

De acordo com Timothy Ireland, assessor da UNESCO Brasil, em documento apresentado na reunião da Comissão Nacional de Alfabetização e Educação de Jovens e Adultos (CNAEJA) e Ministério da Educação (MEC) em fevereiro de 2008, as CONFINTEAs vêm sendo realizadas desde 1949 e ocorrem a cada 12 anos, aproximadamente. Conforme nos explica o referido autor, no plano formal da UNESCO, as Conferências Internacionais de Educação de Adultos são conferências intergovernamentais, o que pressupõe que os Estados-membros sejam convidados a enviar delegações e participar do processo preparatório.

De acordo com o quadro apresentado por Ireland (2008), a primeira CONFINTEA ocorreu na Dinamarca, tendo como temas principais a educação de pessoas adultas 
como instrumento de resistência ao totalitarismo e difusão da cultura de paz e incentivo às campanhas de alfabetização nos países considerados "atrasados". A segunda Conferência ocorreu em 1960, no Canadá, focalizando o papel do estado na educação de adultos e esta, como oportunidade remedial e parte do sistema educacional. A terceira CONFINTEA aconteceu em 1972, no Japão. Nesta Conferência, além de temas como a educação de adultos e alfabetização, mídia e cultura, apareceu o tema aprendizagem ao Longo da Vida, influenciado pelo relatório Aprender a ser - a educação do futuro, coordenado por Edgar Faure, publicado naquele mesmo ano. A quarta CONFINTEA ocorreu 1985, em Paris. Nesta, destacaram-se temas como a educação de adultos e aprendizagem ao longo da vida, o direito a aprender, novas tecnologias da informação e o papel de estados e ONGs. Já a quinta Conferência, ocorrida em 1997, na Alemanha, deu destaque, dentre outros temas, à aprendizagem de adultos como direito, ferramenta, prazer e responsabilidade compartilhada; aprendizagem de adultos e participação ativa em todas as dimensões do desenvolvimento sustentável com equidade; papel da alfabetização: equidade e reconhecimento das diferenças (IRELAND, 2008).

Em 2003, na Tailândia, foi realizado um Balanço Intermediário da CONFINTEA (+ 6), "a qual teve como objetivo a chamada de responsabilização para os estados membros implementarem a Agenda de Hamburgo + chamada para CONFINTEA VI em 2009" (IRELAND, 2011, p. 17). Por fim, a sexta CONFINTEA, retomando as metas do milênio e chamando atenção para o Monitoramento necessário para garantir a sua implementação (IRELAND, 2008).

Para o âmbito desse trabalho, é importante salientar que a V CONFINTEA abordou de forma mais explícita o conceito de aprendizagem ao longo da vida, cujos temas foram assim sintetizados por Di Pierro (2011, p. 7) "aprendizagem ao longo da vida como instrumento de fomento à participação dos cidadãos na promoção do desenvolvimento sustentável com equidade. Reconhecimento da diversidade sociocultural e adoção de perspectiva de gênero".

Sobre a VI CONFINTEA, a autora identifica como objetivos principais, a promoção do reconhecimento da aprendizagem ao longo de toda a vida, tendo a alfabetização como a base, "destacar o papel crucial da EJA para as agendas de educação e 
desenvolvimento" e "renovar o compromisso político dos países com a EJA e passar da retórica à ação (DI PIERRO, 2011, p. 9).

Importante frisar que nesta última Conferência, objeto de nosso estudo, a aprendizagem ao longo da vida foi indicada como "uma filosofia, um marco conceitual e um princípio organizador de todas as formas de educação [...]" (BRASIL, 2010, p. 3).

\section{CONFINTEA VI- arauto para a concretização da educação de jovens e adultos na perspectiva da educação e aprendizagem ao longo da vida?}

No mesmo ano de realização da CONFINTEA VI, realizada em Belém (Brasil), o Instituto da UNESCO para a Aprendizagem ao Longo da Vida - UIL publicou o Global Report on Adult Learning and Education (GRALE), traduzido e publicado no Brasil em 2010 sob o título Relatório Global sobre Aprendizagem e Educação de Adultos. A natureza desse documento é curiosa, pois, ao circular no Brasil na sua versão traduzida em fase posterior a VI CONFERÊNCIA, parece não apenas operar como um documento norteador para o debate, mas, também como documento de síntese dos debates ocorridos naquela Conferência, ainda mais quando apresenta que "este Relatório fornece evidências para apoiar o documento final da reunião [CONFINTEA]" (UNESCO, 2010, p. 12).

Trata-se de um documento bastante ousado, cuja elaboração toma por base Relatórios Nacionais de 154 Estados Membros da UNESCO, documentos estes elaborados em etapa preparatória a VI CONFINTEA. O Relatório Global... anuncia-se, assim, como um documento de análise de tendências, desafios a serem superados e melhores práticas a serem seguidas.

Já no começo do documento, o leitor depara-se com a seguinte constatação entoada pelo ex-Diretor Geral da UNESCO, Koïchiro Matsuura:

A aprendizagem ao longo da vida está no cerne da missão da UNESCO. Desde a sua fundação, a Organização tem desempenhado papel pioneiro na defesa da função crucial da educação de adultos no desenvolvimento da sociedade e na promoção de uma abordagem global de aprendizagem ao longo da vida. (UNESCO, 2010, p. 8) 
Do que fala o documento? Reconhece nesse escopo, aulas de alfabetização para a promoção de "empoderamento", colocando os sujeitos em condições de continuar a aprender; cursos de formação profissional para melhorar as expectativas de emprego, programas de capacitação para a vida, que incluam, por exemplo, aspectos de prevenção relativos a doenças como o HIV; aprendizagem do uso de tecnologias de informação e comunicação.

Para demarcar a compreensão acerca do papel da educação de adultos na contemporaneidade, o documento revisita algumas definições estabelecidas em Nairóbi, por ocasião da aprovação da Recomendação de Nairóbi para o Desenvolvimento da Educação de Adultos (1979), das quais interessa-nos, sobretudo, a de educação de adultos; educação e aprendizagem ao longo da vida. Antes, porém, vale a pena chamar atenção para o fato de que o Relatório Global utiliza apenas a nomenclatura educação de adultos, indicando que "no âmbito de um paradigma de aprendizagem ao longo da vida, é cada vez menos útil fazer distinções rígidas entre 'educação de jovens' e 'educação de adultos'" (UNESCO, 2010, p. 14).

Seguem as definições revisitadas:

Educação de Adultos 'denota o conjunto de processos educacionais organizados, seja qual for o conteúdo, nível e método, quer sejam formais ou não, quer prolonguem ou substituam a educação inicial nas escolas, faculdades e universidades, bem como estágios profissionais, por meio dos quais pessoas consideradas adultas pela sociedade a que pertencem desenvolvem suas habilidades, enriquecem seus conhecimentos, melhoram suas qualificações técnicas ou profissionais ou tomam uma nova direção e provocam mudanças em suas atitudes e comportamentos na dupla perspectiva de desenvolvimento pessoal e participação plena na vida social, econômica e cultural, equilibrada e independente; contudo, a educação de adultos não deve ser considerada como um fim em si, ela é uma subdivisão e uma parte integrante de um esquema global para a educação e a aprendizagem ao longo da vida'. (Recomendação sobre o Desenvolvimento da Educação de Adultos, UNESCO, 1976 apud UNESCO, 2010, p. 13, grifos no original)

Educação e aprendizagem ao longo da vida 'denota uma proposta geral destinada a reestruturar o sistema de educação já existente e desenvolver todo o potencial educacional fora do sistema educacional. Nessa proposta, homens e mulheres são os agentes de sua própria educação, por meio da interação contínua entre seus pensamentos e ações; ensino e aprendizagem, longe de 
serem limitados a um período de presença na escola, devem se estender ao longo da vida, incluindo todas as competências e ramos do conhecimento, utilizando todos os meios possíveis, e dando a todas as pessoas oportunidade de pleno desenvolvimento da personalidade; os processos de educação e aprendizagem nos quais crianças, jovens e adultos de todas as idades estão envolvidos no curso de suas vidas, sob qualquer forma, devem ser considerados como um todo'. (Recomendação sobre o Desenvolvimento da Educação de Adultos, UNESCO, 1976 apud UNESCO, 2010, p. 13, grifos no original)

Tais definições estão na base de sustentação dessa perspectiva educacional, disseminada como diretriz orientadora para as políticas dos países signatários, fundada na ideia de aprendizagem ao longo da vida, afigurada ao longo do Relatório Global como “educação sem fronteiras”, “oportunidades abertas, flexíveis e pessoalmente relevantes", "contextos de aprendizagem e processos atraentes e adaptados" (UNESCO, 2010, p. 14), "continuum de aprendizagem que vai desde a educação formal e passa pela educação não formal e informal (UNESCO, 2010, p. 22), inclui "reciclagem e aprendizagens de novas competências", "maior protagonismo aos indivíduos” (UNESCO, 2010, p. 23). Nessa lógica, o “empoderamento" dos indivíduos é reivindicado como argumento essencial em prol da educação de adultos. É consoante a essa perspectiva que o Relatório anuncia, tal como um arauto, a aprendizagem ao longo da vida como um marco de referência para as políticas dos países, não apenas um marco conceitual, mas político, convertido em legislações e novos modelos de governança, o que envolve diretamente o financiamento e sinergias, com uma aliança tripartite (governos, setor privado e sociedade civil) e novos modos de provisão.

Interessante destacar que o Relatório Global, foi elaborado tendo como referência relatórios de cinco grandes regiões, assim consideradas: Estados Árabes, Ásia-Pacífico, Europa e América do Norte, América Latina e Caribe, África Subsaariana, totalizando 154 países. No que se refere à América Latina e Caribe, as informações contempladas dizem respeito aos seguintes países: Argentina, Brasil, República Dominicana, Equador, Jamaica, Peru, Santa Lúcia. O que nos faz depreender que apenas estes países enviaram os seus relatórios.

Não obstante os avanços e múltiplas experiências elencadas no Relatório Global, o mesmo documento indica seis fatores a serem superados a partir da VI CONFINTEA, 
justificando que "é imperativo passar da retórica à ação" (UNESCO, 2010, p. 25). Dentre esses fatores, destacam-se a carência de clareza conceitual acerca do que constitui a aprendizagem ao longo da vida e o lugar da aprendizagem e educação de adultos nessa perspectiva; a estreita associação da educação de adultos com a alfabetização e o desenvolvimento de competências básicas; o terceiro aspecto refere-se ao fato de que pela própria natureza da oferta de educação de adultos, por vezes fundadas em contextos e métodos não formais e informais de educação, não garante, em muitos casos, credenciamentos formais, neste caso, referem-se a valores comerciais e sociais; o quarto aspecto refere-se aos baixos financiamentos públicos e distribuição desigual de recursos; o quinto leva em conta os profissionais envolvidos com a educação de adultos. Indica-se, nesse ponto uma baixa profissionalização; por último, destacam a dispersão e diversidade dos atores na educação de adultos, resultando em pouco compartilhamento de agendas comuns (UNESCO, 2010, p. 24-25).

Nessa linha de constatações e prescrições, o referido Documento reforça veementemente a necessidade de estabelecimento de um marco de governança da educação de adultos, que a assuma como um direito de todos e para sua efetivação, "o reconhecimento de um continuum de aprendizagem entre a educação formal, não formal e informal" (UNESCO, 2010, p. 27). Nesse sentido, parece constituir-se como alternativa para os países pouco desenvolvidos, é o que pode se depreender dessa passagem:

Nos países que têm infraestruturas de educação pouco desenvolvidas, é difícil estabelecer os tipos de sistemas abrangentes de treinamento e educação formal que existem nos países mais ricos. Efetivamente, a aprendizagem em contextos não formais e informais é a opção mais realista nesses países. (UNESCO, 2010, p. 27)

Se, por um lado, o Relatório reconhece a inexistência de uma clareza conceitual global sobre esse conceito ou marco para as políticas nacionais, por outro, apresenta um rico quadro com exemplos das principais legislações e políticas específicas de aprendizagem e educação de adultos introduzidas desde 1997 (UNESCO, 2010). O que nos leva a pensar, que, não necessariamente os países reconhecem tais atividades 
voltadas à educação de adultos na perspectiva de uma aprendizagem ao longo da vida, mas o Relatório assim os enquadra. Note-se, também, que em alguns casos, a exemplo da Coréia do Sul, Estônia, dentre outros, essa perspectiva fica muito evidente no plano normativo e legislativo. No primeiro país, foi aprovada em 2007 a Lei da Educação ao Longo da Vida; no segundo país, em sintonia com a Comunidade Europeia, foi aprovada a Estratégia de Aprendizagem ao Longo da Vida, 2005-2008 (UNESCO, 2010).

Com base nos dados apresentados, especialmente nesse quadro, o Relatório sintetiza cinco tendências que expressam o momento ou objetivos das políticas voltadas aos adultos, nesses países: a) definição do marco na perspectiva de aprendizagem ao longo da vida; b) promoção da alfabetização e educação não formal; c) regulamentação da formação profissionalizante; d) criação de agendas especializadas; c) dispositivo para a implementação de programas específicos (UNESCO, 2010).

Depreende-se que esta perspectiva educacional encontra-se em distintas fases nos diferentes países, haja vista a especificidade da história e história da educação dos países. Essa constatação sugere a necessidade de aprofundarmos os estudos sobre a circulação, disseminação e apropriação dessa perspectiva educacional em âmbito nacional e regionais, pois, se é fato, que vive-se a transição para uma aprendizagem ao longo da vida, como sugere o Relatório, num evidente movimento de hegemonia discursiva, as apropriações desta transição denotam, na acepção de Braudel (1992), os diferentes tempos do mundo ou na clássica acepção marxista, o lugar que os países ocupam na Divisão Internacional do Trabalho.

O grau de imersão dos países em pobreza generalizada, altos níveis de desigualdade interna e dívida internacional influencia os rumos da formulação de políticas de educação de adultos. Por exemplo, na África Subsaariana, nos Estados Árabes, e em grande parte da Ásia-Pacífico e da América Latina e do Caribe a educação de adultos é equiparada à alfabetização de adultos e à educação compensatória ou de "segunda oportunidade". (UNESCO, 2010, p. 33)

Outros países (principalmente os países nórdicos da Europa) enfatizam o modelo de "bem público" e estão fortemente comprometidos com a 
educação ao longo da vida como um esforço humanístico para o desenvolvimento pessoal e cívico, bem como para o desenvolvimento de recursos humanos. (UNESCO, 2010, p. 33)

\section{Mediações nacionais e regionais: algumas aproximações}

Conforme exposto anteriormente, o Relatório Global lançou aos países signatários alguns desafios a serem superados, dentre eles, um novo modelo de governança, definido como "instituições, regras e normas por meio das quais as políticas são desenvolvidas e implementadas - e por meio das quais a responsabilidade é imposta" (UNESCO, 2008 apud UNESCO, 2010, p. 35), em outras palavras, a defesa de uma desconcentração da governança na educação de adultos posta como "um imperativo político (e talvez até mesmo econômico)" (UNESCO, 2010, p. 39). Nesse sentido, são mencionadas diferentes formas de provisão da educação de adultos, aliança tripartite e a superação de barreiras institucionais, recomendando-se, para isso, a persuasão do setor privado na melhoria da "aprendizagem nos locais de trabalho" (UNESCO, 2010, p. 77) ou o uso do "tipo de flexibilidade e a capacidade de inserção nas comunidades que as ONGs oferecem (UNESCO, 2010, p. 77).

Pois bem, estas são algumas orientações aos países. Mas, quais as ressonâncias dessas orientações em âmbito nacional e, mais especificamente, no estado de Santa Catarina?

Para as análises, foram essenciais os documentos preparatórios (nacionais e regionais) para a VI CONFINTEA e os documentos dela resultantes. Destacam-se: 1. Programa. Confintea VI - Sexta Conferência Internacional de Educação de Adultos. Vivendo e aprendendo para um futuro viável: o poder da aprendizagem e da educação de adultos (2009); 2. O Documento Nacional Preparatório a VI Conferência Internacional de Educação de Adultos (BRASIL, 2009); 3. Marco de Ação de Belém (2010); 4. Documento Base Nacional Orientador (2008); 5. Relatório Final. Encontro estadual da Educação de Jovens e Adultos de Santa Catarina preparatório para a VI CONFINTEA. Educação e Aprendizagem de Jovens e Adultos ao Longo da Vida (2008). 
Logo no início do documento Programa. Confintea VI - Sexta Conferência Internacional de Educação de Adultos. Vivendo e aprendendo para um futuro viável: o poder da aprendizagem e da educação de adultos (2009) tem-se o anúncio do objetivo da CONFINTEA VI, como “oportunidade de construção de uma plataforma única para preparar o terreno para políticas de aprendizagem de adultos que sejam mais inovadoras, abertas e flexíveis" (BRASIL, 2009, p. 2). Localizada como uma perspectiva abrangente, tal como definida no Relatório Global, a educação ao longo da vida é apresentada como estratégia de combate à pobreza e vulnerabilidade, condição para a empregabilidade e exercício da cidadania ativa. Tratada no âmbito do direito, anuncia-se a criação de sistemas de aprendizagem ao longo da vida como condição para o seu exercício.

Nesse sentido, conforme mencionado em Rodrigues e Cavalheiro (2013), são referidas ações políticas com o intuito de desenvolver e fortalecer o reconhecimento da aprendizagem não formal, informal e experiencial e estratégias de governança que incluam o público, privado, ONGs, e a sociedade civil, em consonância com a perspectiva anunciada no Relatório Global, de uma aliança tripartite.

Os temas dos painéis são bastante sugestivos e os representantes dos países presentes nas Mesas também nos oferecem pistas para pensar o lugar dessa Conferência nas políticas nacionais e as adesões dos agentes locais. Nesse sentido, destaca-se, por exemplo, que o Brasil foi representado pela ONG Ação Educativa no Painel 1 - Inclusão e participação de adultos. Além disso, destacam-se os extensivos agradecimentos "ao SESI, a ITAIPU e a Fundação Roberto Marinho por patrocinar o programa cultural" (BRASIL, 2009, p. 9).

O Documento Nacional Preparatório à VI Conferência Internacional de Educação de Adultos (BRASIL, 2009) sistematiza o debate que antecedeu a Conferência realizada em dezembro de 2009. Trata-se de um riquíssimo documento que apresenta constatações de avanços e persistência de situações de exclusão do sistema educacional brasileiro. Chama atenção, sobretudo, a perspectiva de uma educação ao longo da vida em oposição à forma escolarizada e a sua suposta capacidade de equacionar problemas geracionais. Aponta para algumas especificidades nacionais, tais como a necessidade de 
superação da EJA como suplência, e, por conseguinte, para a relação da EJA no Sistema Nacional de Educação, e tratamento isonômico de educandos de EJA. Além disso, esse Documento grifa outro aspecto já salientado no Relatório Global, os profissionais atuantes na EJA. Se, no Relatório Global enfatiza-se a falta de profissionalidade, aqui, considera-se haver uma docência "que se constitui conjuntamente a um estatuto próprio da EJA, na produção e acúmulo de saberes teórico-metodológicos, o que leva à defesa de uma sólida formação de nível superior para a docência na EJA” (BRASIL, 2009, p. 32).

O Documento Marco de Ação de Belém reitera muitas das constatações e prescrições anunciadas tanto no Relatório Global, quanto nos documentos preparatórios nacionais. Neste, reafirma-se a concepção da educação/aprendizagem ao longo da vida como ideal a ser conseguido, “do berço ao túmulo", como "uma filosofia, um marco conceitual e um princípio organizador de todas as formas de educação" (BRASIL, 2010, p. 3). Para a consecução de uma concepção ampliada da EJA fundamentada na educação e aprendizagem ao longo da vida, ocupa centralidade neste Documento, a reafirmação da alfabetização como alicerce para a construção de aprendizagens abrangentes e ao longo de toda a vida, na perspectiva do "empoderamento" e o desenvolvimento de uma boa governança. Nessa direção, são recomendadas a participação de todos os parceiros e a cooperação transnacional, "por meio de projetos e redes de compartilhamento de conhecimentos e práticas inovadoras" (BRASIL, 2010, p. 10).

No âmbito regional, especificamente em Santa Catarina, a análise do debate, das apropriações, divergências ou disputas, requer, sem sombra de dúvidas, um estudo minucioso sobre o próprio histórico e funcionamento dos Fóruns regionais e seus espaços de discussões e deliberações, além de outros aspectos sobre os diálogos e espaços de oitiva e deliberação entre os Fóruns, Secretarias, Ministérios, etc.

A história do Fórum de Educação de Jovens e Adultos de Santa Catarina liga-se à história desse Fórum no Brasil, ao seu surgimento no Rio de Janeiro em 1996, por ocasião das organizações locais e nacionais preparatórias a V Conferência Internacional sobre Educação de Adultos (1997). Em Santa Catarina, em outubro de 1998 foi realizado um Seminário, cujo propósito, era "consolidar a política de EJA no país e estimular a Formação dos Fóruns Regionais desta modalidade de ensino" (HISTÓRICO, 2013), evento 
este, que parece ter contribuído para a continuidade dos debates ao longo dos anos subsequentes, inclusive sobre os debates em torno do Fórum como um espaço não governamental, o que ocorreu oficialmente, em novembro de 1999. Note-se, que na esteira desse processo de criação do Fórum Estadual, aconteceram as mobilizações para a criação dos Fóruns Regionais, o que evidencia ainda mais a complexidade dessa rede de relações.

No que se refere à participação do Fórum Estadual de Santa Catarina no processo de preparação a VI CONFINTEA, esse tema ainda carece de ampla investigação. Sobre esse processo, é possível acessar o documento Relatório Final. Encontro estadual da Educação de Jovens e Adultos de Santa Catarina preparatório para a VI CONFINTEA. Educação e Aprendizagem de Jovens e Adultos ao Longo da Vida (2008), que resultou do III Encontro Estadual de EJA, que teve como lema "Educação e Aprendizagens de Jovens e Adultos ao Longo da Vida", com o objetivo de subsidiar o debate da VI CONFINTEA e “discussões sobre o estado da oferta e das políticas públicas que envolvem a Educação de Jovens e Adultos em Santa Catarina e no Brasil” (ENCONTRO ESTADUAL DA EDUCAÇÃO DE JOVENS E ADULTOS DE SANTA CATARINA, 2008, p. 3 ).

O referido estudo, que compôs o Relatório Nacional sobre a situação da Educação e Aprendizagem de Adultos, que o Brasil enviaria à UNESCO para sistematização do Relatório Global, menciona, além do objetivo acima descrito, contribuir "para a construção de políticas estratégicas de implantação e/ou fortalecimento desta modalidade educacional em cada estado e município brasileiro, em níveis municipal, estadual e federal" (ENCONTRO ESTADUAL DA EDUCAÇÃO DE JOVENS E ADULTOS DE SANTA CATARINA, 2008, p. 3).

Tendo por base o banco de dados apresentado pelo EDUDATA - Sistema de Estatísticas Educacionais (2006), o Relatório Final expõe que a taxa de analfabetismo funcional em Santa Catarina, considerando pessoas maiores de 15 anos de idade, é de 15,13\%. E a sua demanda de atendimento na EJA é de 49,67\% (56\% na zona urbana e 44\% na zona rural) (ENCONTRO ESTADUAL DA EDUCAÇÃO DE JOVENS E ADULTOS DE SANTA CATARINA, 2008). 
Não obstante o reconhecimento de que em Santa Catarina os sistemas públicos de ensino "assumem parte significativa da oferta de EJA no estado, o que correspondeu a 126.668 (cento e vinte e seis mil e seiscentos e sessenta e oito) matrículas no ano de 2007" ( ENCONTRO ESTADUAL DA EDUCAÇÃO DE JOVENS E ADULTOS DE SANTA CATARINA, 2008, p.6), os dados de analfabetismo acima mencionados revelam, segundo o Documento, a necessidade de construção de políticas públicas voltadas para o direito de educação para todos, que não se detenha somente às aprendizagens formais.

Nessa perspectiva de diversificação de ofertas, provisões de atendimento, nos termos da UNESCO, o Relatório indica que em Santa Catarina é possível identificar diferentes atendimentos educativos e ideários presentes nas Propostas Pedagógicas, tais como, princípios da Andragogia, ideários de Paulo Freire, etc. Sobre as metodologias e atendimentos educativos, o Relatório destaca uma ampla variedade, como se pode observar:

\footnotetext{
Metodologias: Ensino por oficinas, Pedagogia da Alternância, Freqüência Diária Obrigatória, Telecurso 2000, Exames Supletivos, Saberes da terra, Educação do campo.

Atendimentos Educativos: TELESSALA, Educação Indígena, Educação Carcerária e Adolescentes em Conflito com a Lei, Educação Inclusiva: DA, DV, DM, DF, Alfabetização, Programa Brasil Alfabetizado, Educação Continuada, Casas Familiares Rurais e do Mar, Educação Afrodescendentes, Outros. (ENCONTRO ESTADUAL DA EDUCAÇÃO DE JOVENS E ADULTOS DE SANTA CATARINA, 2008, p.10).
}

No que se refere às parcerias e financiamentos, o Relatório também indica um amplo espectro, mas de forma muito superficial. Cita parcerias públicas com a Secretaria da Justiça e Cidadania e Prefeituras Municipais, e outras parcerias, tais como a ARCAFAR - Associação Regional das Casas Familiares Rurais/CELESC - Centrais Elétricas do Estado de Santa Catarina/SESC - Serviço Social do Comércio/Angeloni /SONAE/Supermercado Big - Distribuição Brasil S/A/ SESI - Serviço Social da Indústria.

Quanto às formas de organização do trabalho pedagógico, são relatadas experiências específicas da Educação de Jovens e Adultos nas redes municipais, estaduais e federal, além de atendimentos educativos ofertados em outros espaços e 
por outros agentes. Destacam-se, nesse sentido, experiências de cursos não seriados e não disciplinares, organizados em torno de "pesquisas" realizadas pelos alunos em grupos; organizações pedagógicas seriadas, matriz curricular disciplinar com inserções interdisciplinares; ensino por oficinas, telecurso 2000, por ciclos, projetos de aprendizagem e de pesquisa, aulas de informática e oficinas pedagógicas desenvolvidas na comunidade e articulação com a educação profissional. Aliam-se a estas estratégias, instrumentos de avaliação, tais como: "freqüência, provas e exames; cadernos de registro individuais, portfólios, assembléias, apresentações e relatórios das pesquisas" (ENCONTRO ESTADUAL DA EDUCAÇÃO DE JOVENS E ADULTOS DE SANTA CATARINA, 2008, p.17).

Além da oferta de EJA pelos sistemas municipais e estaduais de ensino, dentre outras formas de atendimento já listadas, o Relatório enfatiza a participação do sistema federal de ensino em Santa Catarina, especialmente em quatro âmbitos: “a) UFSC/PRONERA; b) UFSC/NETI; c) UFSC/com atendimento curso pré-vestibular popular; d) CEFETSC/PROEJA" (ENCONTRO ESTADUAL DA EDUCAÇÃO DE JOVENS E ADULTOS DE SANTA CATARINA, 2008, p.19) e do sistema "S", especialmente as parcerias com o SESI e o SESC, nas metodologias de Ensino Modularizado e Telecurso 2000. São mencionadas também informações, qualificadas de informais, a respeito de outras instituições que ofertam cursos de EJA, é o caso, por exemplo, da BBEducar, Alfalit - uma parceria entre o governo brasileiro e a ONG internacional Alfabetização através da Literatura, na execução do programa Brasil Alfabetizado; Arcafar e parcerias; Pastoral da Criança e Pastoral do Idoso - Educação de Jovens e Adultos (ENCONTRO ESTADUAL DA EDUCAÇÃO DE JOVENS E ADULTOS DE SANTA CATARINA, 2008).

O Documento oferece inúmeras possibilidades de análise. Em seu fechamento apresenta recomendações e compromissos para a educação de jovens e adultos em Santa Catarina, chamando atenção para ações imprescindíveis para viabilização das metas e ações de médio e longo prazos, que expressam, em grande medida, as demandas nacionais e regionais colocadas em evidência, que parecem ecoar em vários documentos nacionais e fóruns; trata-se do tratamento isonômico da EJA em relação às outras modalidades de ensino; o reconhecimento da EJA como direito do cidadão "e garantia de 
ser ofertada não mais na forma de programas pontuais/eventuais ou filantrópicos, mas como políticas públicas efetivas" (ENCONTRO ESTADUAL DA EDUCAÇÃO DE JOVENS E ADULTOS DE SANTA CATARINA, 2008, p. 29).

\section{Considerações finais}

Analisar as repercussões e influências da CONFINTEA VI nas Políticas de Educação para Jovens e Adultos em Santa Catarina pareceu-nos nesse processo de pesquisa e de escrita, algo ainda prematuro, que demandará ainda muitas análises, considerando um rol mais abrangente de fontes, incluindo as fontes orais e outras decorrentes dos variados espaços de formulação e implementação das políticas educacionais.

Não obstante essa constatação, gostaríamos de destacar alguns indícios importantes que essa trajetória permitiu vislumbrar. Comecemos pelo reconhecimento da necessária reflexão sobre as mediações internacionais, nacionais e regionais. É impossível fazer uma transposição do conceito de educação e aprendizagem ao longo da vida tal como ele tem sido acalentado no seio da UNESCO desde sua formulação e ajustes operados ao longo do século XX e início deste novo século. Tal conceito, reproduzido incessantemente por sua suposta positividade e imparcialidade no plano das relações econômicas mundiais, encontra as especificidades nacionais e regionais, que não necessariamente reconhecem os conceitos como têm sido reiterados amplamente nos documentos oficiais e oficiosos; expressão disso é o termo governança, que parece não ter sido assimilado em âmbito regional, não obstante o reconhecimento da importância de políticas descentralizadas.

Por outro lado, percebemos uma pressão não tão velada para que todas as ações listadas nos Relatórios nacionais e regionais, incorporados no Relatório Global..., sejam vistas e compreendidas no bojo de uma educação de adultos pautada na perspectiva de uma aprendizagem ao longo da vida. O peso que exerce essa constrição, não é possível perceber na imediaticidade, mas, é possível inferir que há visivelmente uma recolocação intencional desse conceito, forjada como uma unidade global. E, nesse sentido, preocupanos, o modo como, por vezes, o conceito educação e aprendizagem ao longo da vida são 
incluídos no conjunto de argumentos nacionais, de forma naturalizada, mas compreendida apenas superficialmente, tomada acriticamente como destino inexorável da política voltada aos jovens e adultos.

Indubitavelmente, a VI Conferência Internacional de Educação de Adultos (CONFINTEA) é considerada no plano nacional e internacional o principal agente de indução das políticas para a Educação de Jovens e Adultos, assumindo uma função de anunciadora, um arauto para a concretização da perspectiva da educação e aprendizagem ao longo da vida. Todavia, tais processos de disseminação dependem fundamentalmente dos contextos locais; é nesse ponto que é possível depreender o complexo processo entre os agentes nacionais e internacionais, nomeadamente entre a UNESCO, o Ministério da Educação (MEC) e a Secretaria de Educação Continuada, Alfabetização, Diversidade e Inclusão (SECADI), Secretarias Estaduais e Municipais de Educação e Fóruns de EJA do Brasil. Quer nos parecer, que o âmbito de circulação e disseminação deste debate no âmbito dos Fóruns de EJA, a exemplo do documento regional ao qual tivemos acesso, é muito rico, complexo e diverso, e que, longe de apenas reproduzirem os conceitos, exibem, nitidamente, as agendas regionais no plano das recomendações e compromissos, como pudemos visualizar no Relatório Final do Encontro Estadual da Educação de Jovens e Adultos de Santa Catarina (2008), no qual a disputa no âmbito da consolidação da EJA como política pública pode ser facilmente iluminada.

\section{Referências}

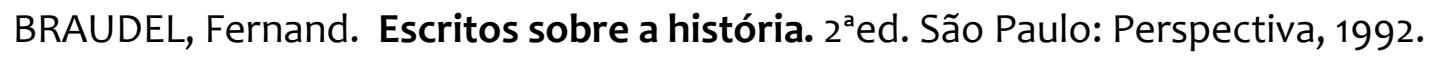

BRASIL. CONFINTEA VI. Marco de ação de Belém. Brasília: UNESCO, MEC, 2010.

BRASIL. Ministério da Educação. SECADI. Documento nacional preparatório à

VI Conferência Internacional de Educação de Adultos: (VI CONFINTEA). Brasília: MEC; Goiânia: FUNAPE/UFG, 2009. 
BRASIL. Ministério da Educação. SECAD. Documento base nacional preparatório à VI CONFINTEA. Brasília: MEC/SECAD, 2008. Disponível em:

<http://forumeja.org.br/files/docbrasil.pdf >. Acesso em 15 de Março de 2012.

CONFERÊNCIA INTERNACIONAL DE EDUCAÇÃO DE ADULTOS, VI. Belém, Pará, Brasil, 1-4 de dezembro de 2009. Programa. Brasília: UNESCO, CONFINTEA VI, Instituto da Unesco para aprendizagem ao longo da vida; MEC/Brasil. 2009. Tema do evento: Vivendo e aprendendo para um futuro viável: o poder da aprendizagem e da educação de adultos.

CONFERÊNCIA NACIONAL DE EDUCAÇÃO BÁSICA, Brasília, abril 2008. Texto referência para debate. Brasília: MEC, 2008a. Disponível em:

$<$ http://portal.mec.gov.br/arquivos/conferencia/documentos/docreferencia.pdf $>$. Acesso em 10 de outubro de 2008.

CONFERÊNCIA NACIONAL DE EDUCAÇÃO BÁSICA, Brasília, abril 2008b. Documento base. Brasília: MEC, 2008b. Disponível em:

<http://portal.mec.gov.br/arquivos/conferencia/documentos/documento_base.pdf>. Acesso em 10 de outubro de 2008.

CONFERÊNCIA NACIONAL DE EDUCAÇÃO BÁSICA, Brasília, abril 2008c. Documento final. Brasília: MEC, 2008c. Disponível em:

$<$ http://portal.mec.gov.br/arquivos/conferencia/documentos/doc_final.pdf $>$. Acesso em 10 de outubro de 2008.

CURY, Carlos Roberto Jamil. O público e o privado na história da educação brasileira: concepções e práticas educativas. In: LOMBARDI, José Claudinei; JACOMELI, Mara Regina Martins; SILVA, Tânia Mara Tavares da. (Orgs.) . O público e o privado na história da educação brasileira: concepções e práticas educativas. Campinas, SP: Autores Associados, 2005, p. 3-28.

DI PIERRO, Maria Clara. A Unesco e os compromissos internacionais sobre políticas de educação de jovens e adultos. Disponível em: <http://www.ceeja.ufscar.br/unesco >. Acesso em 02 de agosto de 2011.

ENCONTRO ESTADUAL DA EDUCAÇÃO DE JOVENS E ADULTOS DE SANTA CATARINA. Educação e aprendizagem de jovens e adultos ao longo da vida. Florianópolis, 28 de março de 2008. Relatório final. 2013. Disponível em: <http://forumeja.org.br/sc/files/Documento\%20Estado\%20SC\%202008.doc $>$. Acesso em 19 de Janeiro de 2013. 
HISTÓRICO do Fórum Estadual de EJA de Santa Catarina. In: Fórum de Educação de Jovens e Adultos de Santa Catarina, [site]. 2013. Disponível em:

<http://forumeja.org.br/sc/node/3 >. Acesso em 19 de janeiro de 2013.

IRELAND, Timothy Denis. Contextualização dos CONFINTEA's anteriores à CONFINTEA VI. In: UNESCO. CONFERÊNCIA INTERNACIONAL DE EDUCAÇÃO DE ADULTOS - CONFINTEA. 2008, Salvador - BA. Salvador, 2008. Documento apresentando na reunião da CNAEJA/MEC, 25 e 26/02/08, Salvado-BA. Disponível em:

<http://forumeja.org.br/files/contextoconfintea.pdf>. Acesso em novembro de 2011.

IRELAND, Timothy Denis. Revisitando a CONFINTEA: sessenta anos de defesa e promoção da educação de adultos. Revista Brasileira de Educação de Jovens e Adultos, v.. 1, n. 1, p. $14-28,2013$.

MELO, Adriana Almeida Sales de. Os organismos internacionais na condução de um novo bloco histórico. In: NEVES, Lúcia. Maria Wanderley. (Org.). A nova pedagogia da hegemonia. Estratégias do capital para educar o consenso. São Paulo: Xamã, 2005, p. 6982.

NEVES, Lúcia Maria Wanderley. (Org.). A nova pedagogia da hegemonia. Estratégias do capital para educar o consenso. São Paulo: Xamã, 2005.

RODRIGUES, Marilda Merência; CAVALHEIRO, Jéssica Vanessa. CONFINTEA VI e as políticas de educação para jovens e adultos em Santa Catarina: perguntando pelas mediações In: JORNADA HISTEDBR, XI, 23 e 24 de out. de 2013, Cascavel (PR). Anais... 2013. Eixo 2: Politica Educacional, p. 1-18. Disponível em:

<http://www.histedbr.fe.unicamp.br/acer_histedbr/jornada/jornada11/anais.html >. 2013.

RODRIGUES, Marilda Merência. Matrizes e repercussões da Educação ao Longo da vida como política educacional. In: EVANGELISTA, Olinda (Org.). 0 que revelam os slogans na política educacional. SP: Junqueira \& Marin, 2014, p. $203-243$.

SHIROMA, Eneida Oto.; CAMPOS, Roselane Fátima Campos; GARCIA, Rosalba Maria Cardoso. Decifrar textos para compreender a política: subsídios teórico-metodológicos para análise de documentos. Perspectiva. Florianópolis, v. 23, n. 02, p. 427-446, jul./dez. 2005.

SHIROMA, Eneida Oto.; MORAES, Maria Célia Marcondes de; EVANGELISTA, Olinda. Política Educacional. Rio de Janeiro: DP\&A, 2002, $2^{\text {a }}$ edição.

UNESCO. Relatório global sobre aprendizagem e educação de adultos. Brasília: UNESCO, 2010. Disponível em : <http://unesdoc.unesco.org/images/0018/001886/188644por.pdf >. Acesso em 02 de agosto de 2011. 
Recebido em: 31/05/2015

Aprovado em: 21/08/2015

Universidade do Estado de Santa Catarina - UDESC

Centro de Ciências Humanas e da Educação - FAED

Revista PerCursos

Volume 16 - Número 31 - Ano 2015

revistapercursos@gmail.com 